\title{
Stem Cell Therapy and the Heart: A Contemporary Review of the Literature
}

\begin{abstract}
Cardiovascular disease continues to bear a significant and increasing burden on global healthcare resources. Despite significant advances in medical and interventional therapies, cardiovascular disease remains the major cause of death worldwide. Beyond this, chronic congestive heart failure (CHF) affects more than 5 million Americans, only half of whom will survive the next five years. These outcomes data have spawned aggressive research efforts searching for novel therapies and treatments of both ischemic heart disease and CHF. Numerous preclinical studies over the past decade have demonstrated the benefit of stem cell therapies with respect to improvement in cardiac function. More recently, research efforts have shifted to wa rdsclinic al rand omized tria lsexamining the role of stem cell therapy in a variety of cardiac conditions. This review focuses on the current status of cardiac cell based therapy while examining the most recent randomized trials including both ischemic and nonischemic cardiomyopathies with an emphasis on current and future a pplic ation of these novel therapies. Despite ongoing advancements, a variety of obstacles exists and must be addressed prior to widespread clinical implementation of cell-based therapies for the treatment of cardiova scular diseases.
\end{abstract}

\section{Introduction}

The mechanisms and pathogenesis of heart failure are complex. In the setting of coronary heart disease, the presence of scar tissue coupled with the loss of functional myocytes capable of appropriate contraction and relaxation of the ventricle contributes significantly to development of ischemic cardiomyopathy. Acute myocardial infarction results in the loss of approximately 1 billion cardiomyocytes within the left ventricle during the first few hours following the onset of ischemia [1]. Historically, therapy for treatment of such cardiomyopathies has focused on strategies to limit further scar formation and tissue remodeling while promoting the functional capacity of viable myocardium [2]. Traditional therapies have provided a modest improvement in cardiovascular morbidity and mortality; yet, cardiovascular disease continues to account for $30 \%$ of global mortality and remains the single most contributory cause of death worldwide [3]. In addition, there are approximately 5.7 million individuals in the U.S. alone living with CHF, of whom only half will survive the next 5 years. CHF remains responsible for 55,000 deaths and an estimated $\$ 39$ billion USD in healthcare expenditure annually, both of these indices expected to increase exponentially over the next several decades $[3,4]$. While ventricular assist devices and biventricular pacemakers can improve symptoms and longevity in patients with $\mathrm{CHF}$, they are expensive and associated with significant risks and complications. Cardiac transplant remains a limited resource for a very narrow patient population.

Given the impact of CHF on the healthcare system, significant interest surrounds the development of novel therapies that may offer incremental benefit for ischemic heart disease and chronic heart failure. The therapeutic potential of stem cells for cardiac

\section{Journal of}

\section{Cardiobiology}

\section{Rebecca Napier*, Neal L. Weintraub and Adam E. Berman}

Division of Cardiology, Department of Medicine, Medical College of Georgia, Georgia Regents University, Augusta, GA, USA

\section{*Address for Correspondence}

Rebecca Napier, MD, Division of Cardiology, Department of Medicine, Medical College of Georgia, Georgia Regents University, 1120 15th Street BBR 6518A, Augusta, GA 30912, E-mail: rnapier@gru.edu

Copyright: (c) 2014 Napier R, et al. This is an open access article distributed under the Creative Commons Attribution License, which permits unrestricted use, distribution, and reproduction in any medium, provided the original work is properly cited.

Submission: 04 November, 2014

Accepted: 08 December, 2014

Published: 13 December, 2014

Reviewed \& Approved by: Dr. Aleksandar Jovanović, Professor of Experimental Medicine, University of Dundee, UK

regeneration has become an area of intense focus for nearly a decade. Cardiomyocytes, once considered terminally differentiated, have recently been shown capable of limited repair. However, endogenous cardiomyocytes turn over very slowly and cannot efficiently replace damaged myocardium following an ischemic insult [5]. Transplantation of exogenous stem cells into the heart offers the potential to increase the number of cardiomyocytes that are electromechanically coupled and appropriately perfused by newly formed blood vessels [6]. Studies performed to date demonstrate scar size reduction and improved contractility in patients with ischemic cardiomyopathy treated with stem cells with ongoing randomized control trials currently in progress [7].

\section{Cell Sources and Clinical Implications}

Stem cells are defined as having the capacity to self-renew and to differentiate into specialized cell lines including cardiomyocytes. Numerous human cell populations have been studied experimentally, including induced pluripotent cells, bone marrow derived mononuclear cells, mesenchymal stem cells, mobilized CD34+ cells and more recently, cardiac derived c-kit+ stem cells. Many of these lineages show promise in early cardiac stem cell trials in humans [8].

\section{Embryonic stem cells and induced pluripotent stem cells}

Embryonic stem cells possess the innate characteristic of pluripotency, the ability to differentiate into all three germ layers while retaining the property of self-renewal or infinite expansion. In animal models, the use of embryonic stem cells in experimentally induced myocardial infarction and nonischemic cardiomyopathies has demonstrated significant improvement in cardiac function and cellular structure with preservation of electrical integration $[9,10]$. However, their use in the clinical realm has been largely limited not only by ethical concerns related to cell harvesting from early embryonic blastocytes, but also by potential immunologic reactions and the teratogenic potential of infinitely self-renewing cells [6].

Artificially produced induced pluripotent stem (IPS) cells possess many of the beneficial properties of embryonic stem cells and have been refined by reprogramming protocols with the use of microRNAs or recombinant proteins to facilitate differentiation directed toward 
cardiomyocytes. Induced pluripotent stem cells, however, share the potentially teratogenic properties of embryonic stems cells, limiting their current clinical application [11].

\section{Skeletal myoblasts}

Menasche et al. first described the use of stem cells for cardiac repair in 2001 using skeletal myoblasts in a patient with ischemic cardiomyopathy, who showed significant improvement in LV function and viability at 5 month follow up [12]. These findings spawned a Phase I clinical investigation in which patients received skeletal myoblasts via epicardial transplantation at the time of coronary artery bypass grafting [12]. Their results demonstrated improved left ventricular ejection fraction (LVEF), although concern was raised regarding a subset of patients who developed ventricular arrhythmias. Subsequently, a Phase II investigation (MAGIC trial) prospectively enrolled patients who were randomized to receive either skeletal myoblast therapy or standard medical therapy alone. This trial demonstrated no significant change in cardiac function as assessed by left ventricular ejection fraction between the groups. MAGIC was terminated early owing to an observed increased in the incidence of ventricular arrhythmias in the group receiving skeletal myoblasts [13]. Subsequent studies demonstrated the inability of skeletal myocytes to express key proteins essential for appropriate electrical conduction within the myocardium, thus compromising their utility as a clinical cardiac cell therapy [2].

\section{Bone marrow derived cells}

The earliest and most noTable clinical trial involving the use of stem cells from bone marrow for the treatment of post-infarction left ventricular dysfunction was conducted by Strauer et al. in 2002 [14]. Ten patients were enrolled and underwent intracoronary infusion of bone marrow-derived mononuclear cells (a mixed cell population) into the infarct related artery at 5 days following an ischemic event. Three month follow up found significant improvement in stroke volume index, left ventricular end systolic volume and myocardial perfusion with no difference in adverse outcome as compared to the control group [14]. Several additional randomized clinical trials followed, including TOPCARE-AMI that demonstrated an improvement in ejection fraction $(51.6 \pm 9.6 \%$ to $60.1 \pm 8.6 \%[p=0.003]$ ) at 4 month follow up in those enrolled to receive either circulating progenitor cells or bone marrow-derived progenitor cells [15]. The BOOST trial, also a randomized controlled study, enrolled 60 patients to receive either bone marrow-derived stem cells or standard medical therapy. The stem cell treated group demonstrated a $6.7 \%$ absolute improvement in LVEF compared to $0.7 \%$ in the control group at 6 month follow up which was also maintained at 18 months [16]. The randomized, placebo controlled REPAIR-AMI trial enrolled 200 patients to evaluate the efficacy of intracoronary delivery of bone marrow progenitor cells compared to placebo in patients with acute ST elevation myocardial infarction after successful percutaneous coronary intervention. At 4 month follow up, patients receiving treatment with progenitor cells had an improvement in LVEF compared to placebo $(+5.5$ vs $+3.0 \%$, absolute difference $+2.5 \%)$ as well as a statistically significant reduction in adverse clinical events at 1 year follow up [17].

While negative and equivocal randomized studies such as the LateTIME [18] and ASTAMI [19] trials add controversy to the use of bone marrow-derived stem cell therapy for heart disease, combined data and analysis of cohort studies and randomized clinical trials has, overall, demonstrated a favorable efficacy and safety profile. This success has prompted the first Phase III clinical trial, BAMI, currently enrolling a projected 3000 patients with acute ST elevation myocardial infarction and reduced $\mathrm{EF} \leq 45 \%$. Patients will be randomized to bone marrow- derived stem cell therapy via intracoronary infusion versus standard medical therapy after successful percutaneous reperfusion with the primary outcome of time from randomization to death (NCT01569178). Results of this study will no doubt have substantial bearing upon the future application of bone marrow-derived stem cell therapy for heart disease.

Bone marrow-derived mesenchymal stem cells are a particular subpopulation of bone marrow cells capable of differentiation into cartilage, bone or adipose tissue, and their differentiation into cardiomyocyte-like cells has also been exhibited [2]. Recent studies suggest these cells also demonstrate a paracrine function involving secretion of growth factors influencing cell-cell interactions as well as prevention of anti-donor $\mathrm{T}$ cell responses contributing to an immune-privileged state, both of which may enhance cellular repair mechanisms [20]. Chen et al. treated 69 patients with acute infarction with cultured mesenchymal cells delivered through intracoronary infusion, resulting in improvement in end-systolic volume, circumferential shortening, and infarct size [21]. These investigators subsequently examined the use of mesenchymal stem cells in patients with chronic ischemia [22]. In this study, patients who received implantation of autologous bone marrow-derived mesenchymal cells showed significant improvement in perfusion by SPECT imaging, increased exercise tolerance and NYHA functional class, and increased ejection fraction from baseline of $26 \pm 6 \%$ to 37 $\pm 9 \%$ at 3 months [22]. The POSIEDON trial compared autologous and allogeneic bone marrow-derived mesenchymal stem cell transplantation in a dose-escalating fashion in patients with ischemic cardiomyopathy and LV dysfunction [23]. At thirteen months of follow up, favorable LV reverse remodeling as measured via the sphericity index, and reduction of myocardial infarct size, was seen in both allogeneic and autologous cell treated patients. However, a significant change in LV ejection fraction was not observed. It was also noted that lower doses of administered mesenchymal stem cells were associated with the greatest reduction in LV volumes. In the TAC-HFT trial, subjects received mesenchymal or bone marrowderived stem cells with 6-minute walk distance, infarct size reduction and regional myocardial function improved in the mesenchymal cell therapy group though no changes in left ventricular chamber volumes or ejection fraction were observed compared to placebo [24]. These results provide useful insight into the feasibility and continued clinical development of mesenchymal stem cells as a potential cardiac cell based therapy.

\section{Cardiac derived/resident stem cells}

Once thought to be terminally differentiated, it is now widely accepted that the adult myocardium contains small populations of cardiospheres or clusters of surviving resident cardiac stems cells/ progenitor cells capable of differentiating into cardiomyocytes or vascular lineages. Though such cell lines isolated from myocardial biopsy and have high proliferative capability, endogenous populations of these cells cannot compensate for the magnitude of 
injury that typically occurs during an acute myocardial infarction. However, harvesting and expansion of these cells may provide a useful therapeutic source for cardiac repair $[2,25]$. Cardiac stem cells have been identified by expression of various cell surface markers, including c-kit, Sca-1 and Isl-1. In 2003, Beltrami et al. published the first report of the discovery of endogenous stem cells recovered from the mammalian heart marked by the tyrosine kinase receptor c-kit [26]. Subsequent preclinical trials in animal models demonstrated the safety and efficacy of cardiac stem cell transplantation, thereby leading to the first human trial examining the utility of cardiac-derived stem cells obtained via surgical biopsy specimens for the treatment of post infarction left ventricular dysfunction: SCIPIO [27]. At 12-month follow up, the treatment group receiving intracoronary injection of cardiac stem cells had a marked improvement in LVEF as compared to the medical therapy group (from $27.5 \pm 1.6 \%$ to $41.2 \pm 4.5 \%$ $[p=0.013]$ ). Also observed were similar trends in NYHA functional class and quality of life indicators that persisted in those completing 24 month follow up. Infarct regression was also demonstrated by cardiac MRI after in those subjects receiving cell therapy. In addition, no significant difference in adverse events was observed between the treated and untreated groups.

The CADUCEUS trial investigated the use of cardiac-derived cells for the treatment of ischemic heart disease, enrolling patients with recent myocardial infarction ( $<4$ weeks) and LV systolic dysfunction [28]. Patients were randomized to receive cell-based therapy versus standard medical therapy. In the treatment group, intracoronary delivery of cardiac-derived stem cells was performed from 1.5-3 months post-enrollment. A significant regression of infarct mass and increased viable tissue was detected by MRI in the treatment group compared to control. No significant difference was noted in ventricular volumes or ejection fraction between groups. While these results are promising, larger randomized controlled trials are necessary to better define the long term efficacy and clinical utility of cardiac-derived cell therapy in this population.

\section{Methods of Cell Delivery}

The various modes of cell delivery and the timing of cellular injection represent salient areas of clinical investigation and research development. The majority of intravenously delivered stem cells are confined to the liver and lungs, with less than $1 \%$ of infused cells detected within the infarcted heart at 4 hours [29]. However, anti-inflammatory and pro-angiogenic proteins produced by mesenchymal stem cells trapped in extracardiac tissues potentially may produce beneficial effects on the heart, as evidenced by improvement in cardiac function following intravenous delivery of allogeneic mesenchymal stem cells [30].

Intracoronary infusion of cellular suspension directly into a culprit coronary artery vessel is the most frequently used mode of delivery for stem cells in acute myocardial infarction. Similar to intravenous cellular administration, only about $1-3 \%$ of intracoronary delivered cells are retained within the myocardium, with most of the residual being distributed to the liver and lungs. In addition, intracoronary infusion of large cell lineages such as skeletal myoblasts and cultured mesenchymal cells may be associated with mircoinfarction due to vascular obstruction [29].
Direct intramyocardial injection of stem cells has been associated with improved myocardial retention without compromise of coronary blood flow. This method of cellular delivery has been investigated primarily in patients with chronic ischemic disease and LV systolic dysfunction. Intramyocardial cell delivery is typically accomplished via catheter-based percutaneous endoventricular injection, transepicardial approach, or delivery through one of the cardiac veins directly into the myocardium. A specific advantage of percutaneous endoventricular injection is the possibility of real-time 3-dimensional electromechanical mapping to identify and target regions of the myocardium based upon myocardial viability and contractility [31]. In experienced hands, myocardial cell retention is upwards of 20-30\% via catheter based endoventricular delivery [32].

Ongoing research is warranted to determine not only the appropriate cell type and method of cell delivery for cardiac based stem cell treatments, but also to determine the optimal timing of stem cell transplantation. A retrospective analysis of the REPAIR-AMI study demonstrated that a clinical benefit was observed only in those patients receiving bone marrow mononuclear cells 5-7 days after infarction [17]. Additional studies such as the LateTIME trial showed that delayed delivery of autologous bone marrow mononuclear cells 2-3 weeks post-myocardial infarction did not demonstrate improvement in LV function at 6 month follow up [18]. The SWISSAMI trial, which compared post-infarction intracoronary infusion of autologous bone marrow mononuclear cells at 5-7 days or 3-4 weeks, failed to demonstrate benefit on LVEF or infarct size at 4 months assessed by MRI, regardless of timing of delivery [33].

\section{Clinical Application of Stem Cell Therapy in Cardiovascular Disorders}

\section{Acute myocardial infarction}

Combined data from numerous trials have validated the safety and early efficacy of intracoronary infusion of bone marrow-derived stem cells as adjunctive therapy following acute myocardial infarction (Table 1). The largest randomized studies to date include the BOOST trial [16], TOPCARE-AMI [15] and studies by Chen et al. [21]. In the BOOST trial, treatment with bone marrow-derived cells resulted in $6 \%$ relative improvement in $\mathrm{EF}$ at 6 months compared to control, and the improvement was maintained at 18 months. These benefits were noted in addition to those derived from standard interventional and medical care following acute myocardial infarction. Reductions in infarct size and LV end diastolic volume, however, were not observed suggesting a possible limitation of bone marrow-derived cells to modulate LV remodeling [16]. In TOPCARE-AMI, patients were randomized to receive either mononuclear bone marrowderived cells or blood-derived progenitor cells. An $8 \%$ relative improvement in LVEF and a reduction in infarct size were observed at 4 month follow up in the cell therapy groups [15]. One of the largest multicentered randomized controlled trials to date, REPAIRAMI $(n=204)$, demonstrated improvement in LV function following intracoronary infusion of bone marrow-derived mononuclear cells, with benefits persisting at 5 years post-infusion follow up $[17,28]$.

\section{Non-revascularizable coronary artery disease}

Despite advanced percutaneous and surgical techniques, a specific subset of patients with chronic ischemic heart disease 
ISSN: 2332-3671

Table 1: Major randomized and/or landmark trials in cardiac stem cell therapy: Acute myocardial infarction.

\begin{tabular}{|c|c|c|c|c|c|c|c|c|}
\hline Study & Phase & Design & $n$ & Cell Type & $\begin{array}{l}\text { Mode of } \\
\text { Delivery }\end{array}$ & Primary Outcome & Results & Trial Number \\
\hline BOOST & I & RDBPC & 60 & BM-MNC & IC & LVEF & LVEF个 & NCT00224536 \\
\hline LEUVEN-AMI & II & RDBPC & 67 & BM-MNC & IC & LVEF & LVEF - , infarct size $\downarrow$ & NCT00264316 \\
\hline AST-AMI & II & RSBPC & 100 & BM-MNC & IC & LVEF & $\begin{array}{l}\text { LVEF -, LVEDV -, infarct } \\
\text { size - }\end{array}$ & NCT00199823 \\
\hline REPAIR-AMI & III & RDBPC & 204 & BM-MNC & IC & LVEF & $\begin{array}{c}\text { LVEF}, \text { trend toward } \downarrow \\
\text { mortality }\end{array}$ & NCT00279175 \\
\hline REGENT & II & ROPC & 200 & BM-MNC & IC & LVEF & $\begin{array}{c}\text { LVEF -, LVESV -, LVEDV } \\
\text {-, MACE - }\end{array}$ & NCT00316381 \\
\hline LateTIME & II & RDBPC & 87 & BM-MNC & IC & LVEF, regional LV function & $\begin{array}{l}\text { LVEF -, regional LV } \\
\text { function - }\end{array}$ & NCT00684060 \\
\hline TIME & II & RDBPC & 120 & BM-MNC & IC & LVEF, regional LV function & $\begin{array}{l}\text { LVEF -, regional LV } \\
\text { function - }\end{array}$ & NCT00684021 \\
\hline SWISS-AMI & II & ROPC & 200 & BM-MNC & IC & LVEF & LVEF - , infarct size - & NCT00355186 \\
\hline BAMI & III & ROPC & 3000 & BM-MNC & IC & All cause death & Ongoing & NCT01569178 \\
\hline PreSERVE-AMI & II & RDBPC & 160 & CD34 & IC & $\begin{array}{l}\text { serious adverse events, } \\
\text { myocardial perfusion }\end{array}$ & Ongoing & NCT01495364 \\
\hline STEMMI & II & RDBPC & 78 & MSC & IC & Safety & $\begin{array}{c}\text { No increased adverse } \\
\text { events }\end{array}$ & NCT00135928 \\
\hline APOLLO & $1 / I I$ & RDBPC & 13 & MSC & IC & Safety & $\begin{array}{c}\text { LVEF } \boldsymbol{\uparrow}, \\
\text { perfusion defect } \downarrow \\
\text { myocardial scar } \downarrow\end{array}$ & NCT00442806 \\
\hline ADVANCE & $\mathrm{II} / \mathrm{III}$ & RDBPC & 360 & MSC & IC & Safety, infarct size & Ongoing & NCT01216995 \\
\hline ENACT-AMI & II & RDBPC & 100 & EPC & IC & LVEF & Ongoing & NCT00936819 \\
\hline $\begin{array}{l}\text { Mesoblast AMI/ } \\
\mathrm{AMICl}\end{array}$ & & RSBPC & 25 & MSC & $\mathrm{IM}$ & Feasibility, Safety & Ongoing & NCT00555828 \\
\hline PROCHYMAL & II & RDBPC & 220 & MSC & IV & Safety, LVESV & Ongoing & NCT00877903 \\
\hline
\end{tabular}

RDBPC: Randomized Double Blinded Placebo Controlled; RSBPC: Randomized Single Blinded Placebo Controlled; ROPC: Randomized Open-labeled Placebo Controlled; RONPC: Randomized Open-labeled Non-placebo Controlled; BM-MNC: Bone-marrow Mononuclear Cells; MSC: Mesenchymal Stem Cell; EPC: Endothelial Progenitor Cell; IC: Intracoronary; IM: Intramyocardial; IV: Intravenous; LVEF: Left Ventricular Ejection Fraction; LVESV: Left Ventricular; End Systolic Volume; LVEDV: Left Ventricular End Diastolic Volume; MACE: Major Adverse Cardiac Events

may have no options for revascularization. Such individuals may continue to experience refractory angina in addition to myocardial dysfunction with an increased risk of arrhythmia and sudden cardiac death. Transmyocardial injection of stem cells directly into ischemic myocardium via electromechanical mapping guidance was shown to result in improvement of angina symptoms, exercise capacity, regional tissue perfusion and LV systolic function in several small, nonrandomized studies [34]. The PRECISE trial was a randomized controlled study using adipose-derived stem cells to treat non-revascularizable ischemic myocardium that demonstrated an improvement of maximum oxygen consumption by $3.4 \mathrm{ml} / \mathrm{kg} /$ min and a decrease in infarcted myocardium by $8.2 \%$ compared to placebo at 6 month follow up [35]. Larger randomized controlled trials are currently underway with evidence of promising preliminary findings [27]. One such trial, ixCELL DCM (NCT01670981), is a multicentered, randomized, double-blinded, placebo controlled phase II study designed to evaluate the efficacy and safety of catheterbased intramyocardial injection of ixmyelocel-T cells in patients with heart failure due to ischemic dilated cardiomyopathy in whom revascularization in not a reasonable option. Ixmyelocel-T cells are refined autologous hematopoietic cells derived from expanded bone marrow lineages including mesenchymal cells, monocytes and macrophages. The primary outcome measures for this study include all-cause death, cardiovascular hospitalizations, and unplanned outpatient or emergency department visits to treat acute decompensated heart failure over a 12 month follow up period posttreatment. Additional secondary outcomes will include functional assessment via 6-minute walk test, quality of life measures and NYHA classification. Table 2 outlines the major clinical trials evaluating the utility of cell therapy in ischemic cardiomyopathies.

\section{Left ventricular systolic dysfunction and congestive heart failure}

Randomized, double blind control trials have until recently remained lacking in definitive conclusions regarding the efficacy and long-term benefits of cell based therapy for ischemic cardiomyopathy. However, the recently published C-CURE (Cardiopoietic stem Cell therapy in Heart Failure) trial was a prospective, multicentered randomized trial comparing patients receiving standard medical care versus standard care plus adjunctive cell-based therapy [36]. Human bone marrow cells were harvested followed by mesenchymal stem cell isolation, expansion, lineage specification, and cardiopoietic cell expansion. A total of 47 patients were randomized to endocardial injection of cells versus standard of care. Three-dimensional electromechanical mapping was used to define areas of viable and dysfunctional myocardium. Cardiac function assessed by echocardiography demonstrated a 7\% increase in LVEF at 6 months in the cell therapy group (from $27.5 \pm 1.0 \%$ to $34.5 \pm 1.1 \%$ ) while 
Table 2: Major randomized and/or landmark trials in cardiac stem cell therapy: Ischemic cardiomyopathy.

\begin{tabular}{|c|c|c|c|c|c|c|c|c|}
\hline Study & Phase & Design & $n$ & Cell Type & $\begin{array}{l}\text { Mode of } \\
\text { Delivery }\end{array}$ & Primary Outcome & Results & Trial Number \\
\hline MAGIC & II & RDBPC & 97 & SM & IM & MACE, LVEF & 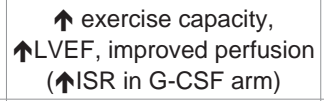 & NCT00102128 \\
\hline SEISMIC & II & ROPC & 40 & SM & IM & Safety, LVEF & LVEF - & NCT00375817 \\
\hline MARVEL & III & RDBPC & 170 & SM & IM & $\begin{array}{l}\text { Safety, QOL, } 6 \text { min } \\
\text { walk at } 1 \text { year }\end{array}$ & $\begin{array}{l}\text { trend toward improved } \\
\text { functional capacity, } \\
\text { increased occurrence VT }\end{array}$ & NCT00526253 \\
\hline ESCAPE & III & RDBPC & 250 & BM-MNC & IM & Survival at 1 year & $\begin{array}{l}\text { LVEF个, improved NYHA } \\
\text { class, improved survival at } \\
1 \text { year }\end{array}$ & NCT00841958 \\
\hline PERFECT & III & RDBPC & 142 & CD133 & IM & LVEF & Ongoing & NCT00950274 \\
\hline FOCUS & II & RDBPC & 92 & BM-MNC & IM & $\begin{array}{l}\text { LVESV, MVO2, } \\
\text { reversible defect }\end{array}$ & $\begin{array}{c}\text { LVESV-, MVO2-, reversible } \\
\text { defect - }\end{array}$ & NCT00824005 \\
\hline TAC-HFT & $\mathrm{I} / \mathrm{II}$ & RDBPC & 60 & MSC/BMC & IM & serious adverse events & Ongoing & NCT00768066 \\
\hline PROMETHEUS & $\mathrm{I} / \mathrm{II}$ & RDBPC & 45 & MSC & IM & serious adverse events & Ongoing & NCT00587990 \\
\hline C-CURE & III & RSBPC & 240 & MSC & IM & LVEF & 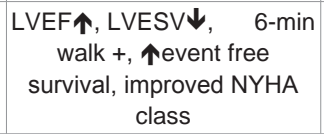 & NCT00810238 \\
\hline RENEW & III & ROPC & 291 & CD34/G-CSF & IM & $\begin{array}{c}\text { exercise tolerance at } \\
1 \text { year }\end{array}$ & Ongoing & NCT01508910 \\
\hline АСТ34-CMI & II & RDBPC & 109 & CD34 & IM & angina frequency & $\begin{array}{l}\text { angina frequency } \downarrow \text {, } \\
\text { exercise tolerance } \uparrow\end{array}$ & NCT00300053 \\
\hline CADUCEUS & I & RONPC & 31 & CDC & IC & serious adverse events & $\begin{array}{c}\text { SAE-, LVEF - , } \\
\text { mass } \downarrow\end{array}$ & NCT00893360 \\
\hline SCIPIO & I & RONPC & 40 & c-kit+ & IC & serious adverse events & 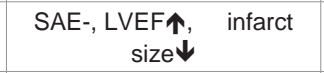 & NCT00474461 \\
\hline ALLSTAR & $1 / I I$ & RDBPC & 274 & CDC & IC & $\begin{array}{l}\text { serious adverse } \\
\text { events, infarct size }\end{array}$ & Ongoing & NCT01458405 \\
\hline REPEAT & II/III & ROPC & 676 & BM-MNC & IC & Mortality & Ongoing & NCT01693042 \\
\hline ixCELL DCM & II & RDBPC & 108 & ixmyelocel-T & IM & $\begin{array}{l}\text { all cause death, CV } \\
\text { hospitalization }\end{array}$ & Ongoing & NCT01670981 \\
\hline
\end{tabular}

RDBPC: Randomized Double Blinded Placebo Controlled; RSBPC: Randomized Single Blinded Placebo Controlled; ROPC: Randomized Open-Labeled Placebo Controlled; RONPC: Randomized Open-labeled Non-placebo Controlled; BM-MNC: Bone-Marrow Mononuclear Cells; MSC: Mesenchymal Stem Cell; SM: Skeletal Myoblasts; CDC: Cardiac Derived Cells; G-CSF: Granulocyte Colony-stimulating Factor; IC: Intracoronary; IM: Intramyocardial; IV: Intravenous; LVEF: Left Ventricular Ejection Fraction; LVESV: Left Ventricular End Systolic Volume; SAE: Serious Adverse Events; NYHA: New York Heart Association Functional Class; QOL: Quality Of Life; ISR: In-stent Restenosis; $\mathrm{MVO}_{2}$ : Maximal Oxygen Consumption; CV: Cardiovascular

remaining essentially unchanged in the control group. In addition, cell therapy significantly reduced LV end systolic volume and improved 6-minute walk distance, NYHA functional class and quality of life as determined by the Minnesota Living with Heart Failure Questionnaire. This study was the first of its kind to demonstrate the potential of cardiogenic lineage-guided cell-based therapy to regenerate myocardium in patients with ischemic heart failure.

Results were recently reported from the TAC-HFT trial, a randomized, blinded, placebo controlled study enrolling 65 patients with ischemic cardiomyopathy and LV systolic dysfunction [24]. Subjects receiving transendocardial injection of mesenchymal or bone marrow-derived stem cells were compared to placebo-treated subjects and followed for 1 year. Quality of life indicators were improved in both cell therapy groups; however, 6-minute walk distance and infarct size was reduced only in the mesenchymal cell therapy group. Despite these findings, no changes in left ventricular chamber volumes or ejection fraction were observed.
The role of stem cell therapy for cardiac repair in nonischemic cardiomyopathies is not yet been clearly defined though several small, randomized controlled trials involving intracoronary infusion of bone marrow derived cells or autologous CD34+ cells have demonstrated improvements in ejection fraction [37]. Table 3 outlines the major clinical trials evaluating the use of cardiac stem cell therapy for nonischemic cardiomyopathies. Additional trials evaluating stem cell therapy in dilated, nonischemic cardiomyopathies are currently underway including REGENERATE-DCM (NCT01302171), a multicenter double-blinded randomized controlled study examining the role of autologous bone marrow-derived cells and granulocyte colony stimulating factor (G-CSF) to improve cardiac function in dilated cardiomyopathy. Another such double-blinded, randomized, sham-procedure controlled phase III trial is currently enrolling a projected 1730 subjects with left ventricular systolic function of either ischemic or nonischemic etiology to determine whether transendocardial delivery of allogeneic human bone marrow-derived mesenchymal precursor cells (CEP-41750) are effective in treating 
ISSN: 2332-3671

Table 3: Major randomized and/or landmark trials in cardiac stem cell therapy: Non-ischemic cardiomyopathy/Dilated cardiomyopathy.

\begin{tabular}{|c|c|c|c|c|c|c|c|c|}
\hline Study & Phase & Design & $n$ & Cell Type & $\begin{array}{l}\text { Mode of } \\
\text { Delivery }\end{array}$ & $\begin{array}{l}\text { Primary } \\
\text { Outcome }\end{array}$ & Results & Trial Number \\
\hline POSEIDON-DCM & $1 / I I$ & RONPC & 30 & MSC & $\mathrm{IM}$ & $\begin{array}{c}\text { serious } \\
\text { adverse events }\end{array}$ & 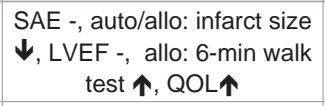 & NCT01087996 \\
\hline REGENERATE-DCM & II & RDBPC & 60 & $\begin{array}{c}\text { BM-MNC vs } \\
\text { placebo/G-CSF }\end{array}$ & IC & LVEF & Completed (results pending) & NCT01302171 \\
\hline NOGA-DCM & II & RSBPC & 90 & CD34 & $\mathrm{IC} / \mathrm{IM}$ & LVEF & Ongoing & NCT01350310 \\
\hline TOPCARE-DCM & II & RONPC & 30 & BM-MNC & IC & LVEF & Completed (results pending) & NCT00284713 \\
\hline CEP-41750 (Teva)* & III & RDBPC & 1730 & allogeneic MPC & $\mathrm{IM}$ & HF-MACE & Ongoing & NCT02032004 \\
\hline
\end{tabular}

RDBPC: Randomized Double Blinded Placebo Controlled; RSBPC: Randomized Single Blinded Placebo Controlled; ROPC: Randomized Open-labeled Placebo Controlled; RONPC: Randomized Open-labeled Non-placebo Controlled; BM-MNC: Bone-Marrow Mononuclear Cells; MSC: Mesenchymal Stem Cell; CDC: Cardiac Derived Cells; G-CSF: Granulocyte Colony-stimulating Factor; IC: Intracoronary; IM: Intramyocardial; LVEF: Left Ventricular Ejection Fraction; SAE: Serious Adverse Events; MPC: Mesenchymal Precursor Cells; HF-MACE: Heart Failure Major Adverse Events; *Study Evaluates Both Ischemic and Non-ischemic Cardiomyopathy

chronic heart failure, with primary outcome measure of time to first heart failure related major adverse cardiac events over a 5 year study period (NCT02032004).

\section{Conclusions}

Substantial advances in cell-based therapy for cardiac disease have evolved over the past decade. Numerous small clinical trials conducted to date have demonstrated modest but encouraging results in terms of clinically accepted endpoints such as recovery of LV systolic function and improvement in quality of life. Over 50 phase I/II trials have demonstrated the use of cell based therapy in the treatment of acute myocardial infarction or chronic heart failure to be both safe and clinically feasible with combined data analysis indicating effectiveness in improvement of ejection fraction and reduction of infarct size [27].

Despite these promising findings, a variety of considerations continue to challenge widespread adoption of cell-based therapies for the treatment of cardiovascular disease. Key concepts such as optimum cell type, timing and method of delivery, and retention of transplanted cardiac cells into host myocardium, pose challenges that must be elucidated prior to widespread implementation of cell therapy in the clinical arena [38].

Currently, clinical cardiovascular guidelines do not include cardiac cell therapies as standard of clinical care and no cell products are commercially available in the US. Ongoing large phase III clinical trials may provide the critical evidence needed for cell therapy to become part of the armamentarium available to treat advanced cardiovascular diseases.

\section{Future Directions}

In its infancy, cardiac stem cell research focused primarily on the replacement of damaged or lost cardiomyocytes. More recently, contemporary cardiac cellular therapy has shifted to the concept of modulating cytokine release and paracrine-related cellular repair. The cytokine-paracrine model considers the primary function of transplanted cells to be enhancement of angiogenesis, reduction of inflammatory responses, and metabolic modulation leading to improved tissue perfusion, reduction of apoptosis and activation of resident cardiac stem cells. Together, these functions lead to increased cellular repair and cytoprotection, with little if any role for the transplanted stem cells themselves to differentiate into cardiomyocytes [6]. Limited retention and survival of transplanted stem cells remains a significant barrier to improving the efficacy of cardiac regenerative therapy. Research into mechanisms to enhance cell homing, migration, and retention include preconditioning or priming of stem cells via induction of ischemia, treatment with pharmacologic reagents and growth factors, hypoxic shock or genetic manipulation to promote cellular resistance and survival against oxidative stress [39]. Such studies are currently underway in several clinical trials including ENACT-AMI, which examines the potential improvement after transplantation of cells transfected with human endothelial nitric oxide synthase (NTC00936819), and the ALCADIA trial (NCT00981006), which incorporates growth factor treatment as a strategy to enhance the reparative capacity of stem cells [7].

Studies thus far have validated the safety of most cardiac cellbased therapies, although patient protection must remain of utmost importance as continued advancements coupled with increased cell retention, survival and regeneration of transplanted cells may alter the clinical course. Ongoing consideration for patient safety in regards to potential arrhythmogenesis, oncogenicity and aberrant cell differentiation, multiorgan seeding and accelerated atherosclerosis must be reevaluated with advancing cell-based therapies [6,38].

\section{References}

1. Murry CE, Reinecke H, Pabon LM (2006) Regeneration gaps: observations on stem cells and cardiac repair. J Am Coll Cardiol 47: 1777-1785.

2. Loughran JH, Chugh AR, Ismail I, Bolli R (2013) Stem cell therapy: promising treatment in heart failure? Curr Heart Fail Rep 10: 73-80.

3. Avery CL, Loehr LR, Baggett C, Chang PP, Kucharska-Newton AM, et al (2012) The population burden of heart failure attribuTable to modifiable risk factors: the ARIC study. J Am Coll Cardiol 60: 1640-1646.

4. Titler MG, Jensen GA, Dochterman JM, Xie XJ, Kanak M, et al. (2008) Cost of hospital care for older adults with heart failure: medical, pharmaceutical, and nursing costs. Health Serv Res 43: 635-655

5. Bergmann O, Bhardwaj RD, Bernard S, Zdunek S, Barnabé-Heider F, et al. (2009) Evidence for cardiomyocyte renewal in humans. Science 324: 98-102.

6. Gersh BJ, Simari RD, Behfar A, Terzic CM, Terzic A (2009) Cardiac cell repair therapy: a clinical perspective. Mayo Clin Proc 84: 876-892.

7. Jakob P, Landmesser U (2013) Current status of cell-based therapy for heart failure. Curr Heart Fail Rep 10: 165-176. 
8. Tongers J, Losordo DW, Landmesser U (2011) Stem and progenitor cellbased therapy in ischaemic heart disease: promise, uncertainties, and challenges. Eur Heart J 32: 1197-1206.

9. Hodgson DM, Behfar A, Zingman LV, Kane GC, Perez-Terzic C, et al. (2004) STable benefit of embryonic stem cell therapy in myocardial infarction. Am J Physiol Heart Circ Physiol 287: H471-H479.

10. Yamada S, Nelson TJ, Crespo-Diaz, Perez-Terzic C, Liu XK, et al. (2008) Embryonic stem cell therapy of heart failure in genetic cardiomyopathy. Stem Cells 26: 2644-2653.

11. Robinton, DA, Daley GQ (2012) The promise of induced pluripotent stem cells in research and therapy. Nature 481: 295-305.

12. Menasche $P$, Hagège AA, Vilquin JT, Desnos $M$, Abergel $E$, et al. (2003) Autologous skeletal myoblast transplantation for severe postinfarction left ventricular dysfunction. J Am Coll Cardiol 41: 1078-1083.

13. Menasche P, Alfieri O, Janssens S, McKenna W, Reichenspurner $\mathrm{H}$, et al. (2008) The myoblast autologous grafting in ischemic cardiomyopathy (MAGIC) trial: first randomized placebo-controlled study of myoblast transplantation. Circulation 117: 1189-1200.

14. Strauer BE, Brehm M, Zeus T, Köstering M, Hernandez A, et al. (2002) Repair of infarcted myocardium by autologous intracoronary mononuclear bone marrow cell transplantation in humans. Circulation 106: 1913-1918.

15. Assmus B, Schächinger V, Teupe C, Britten M, Lehmann R, et al. (2002) Transplantation of progenitor cells and regeneration enhancement in acute myocardial infarction (TOPCARE-AMI). Circulation 106: 3009-3017.

16. Meyer GP, Wollert KC, Lotz J, Steffens J, Lippolt P, et al. (2006) Intracoronary bone marrow cell transfer after myocardial infarction: eighteen months' followup data from the randomized, controlled BOOST (BOne marrOw transfer to enhance ST-elevation infarct regeneration) trial. Circulation 113: 1287-1294.

17. Schachinger V, Erbs S, Elsässer A, Haberbosch W, Hambrecht R, et al. (2006) Improved clinical outcome after intracoronary administration of bone marrow derived progenitor cells in acute myocardial infarction: final 1 year results of REPAIR-AMI trial. Eur Heart J 27: 2775-2783.

18. Traverse JH, Henry TD, Ellis SG, Pepine CJ, Willerson JT, et al. (2011) Effect of intracoronary delievery of autologous bone marrow mononuclear cells 2 to 3 weeks following acute myocardial infarction on left ventricular function: the LateTIME randomized trial. JAMA 306: 2110-2119.

19. Lunde K, Solheim S, Aakhus S, Arnesen H, Abdelnoor M, et al. (2006) Intracoronary injection of mononuclear bone marrow cells in acute myocardial infarction. N Engl J Med 355: 1199-1209.

20. Griffin MD, Ryan AE, Alagesan S, Lohan P, Treacy O, et al. (2013) Anti-donor immune responses elicited by allogeneic mesenchymal stem cells: what have we learned so far? Immunol Cell Biol 91: 40-51.

21. Chen SL, Fang WW, Ye F, Liu YH, Qian J, et al. (2004) Effect on left ventricular function of intracoronary transplantation of autologous bone marrow mesenchymal stem cell in patients with acute myocardial infarction. Am J Cardiol 94: 92-95

22. Chen S, Liu Z, Tian N, Zhang J, Yei F, et al. (2006) Intracoronary transplantation of autologous bone marrow mesenchymal stem cells for ischemic cardiomyopathy due to isolated chronic occluded left anterior descending artery. J Invasive Cardiol 18: 552-556.

23. Hare JM, Fishman JE, Gerstenblith G, DiFede Velazquez DL, Zambrano JP, et al. (2012) Comparison of allogenic vs autologous bone marrow-derived mesenchmal stem cells delivered by transendocardial injection in patients with ischemic cardiomyopathy: the POSEIDON randomized trial. JAMA 308: 2369-2379

24. Heldman AW, DiFede DL, Fishman JE, Zambrano JP, Trachtenberg BH, et al. (2014) Transendocardial mesenchymal stem cells and mononuclear bone marrow cells for ischemic cardiomyopathy: the TAC-HFT randomized trial. JAMA 311: 62-73.

25. Tang YL, Wang YJ, Chen LJ, Pan YH, Zhang L, et al. (2013) Cardiac derived stem cells based therapy for heart failure: progress and clinical application. Exp Biol Med (Maywood) 238: 294-300.

26. Beltrami AP, Barlucchi L, Torella D, Baker M, Limana F, et al. (2003) Adult cardiac stem cells are multipotent and support myocardial regeneration. Cell 114: 763-776.

27. Bolli R, Chugh AR, D'Amario D, Loughran JH, Stoddard MF, et al. (2011) Cardiac stem cells in patients with ischaemic cardiomyopathy (SCIPIO): initial results of a randomized phase I trial. Lancet 378: 1847-1857.

28. Makkar RR, Smith RR, Cheng K, Malliaras K, Thomson LE, et al. (2012) Intracoronary cardiosphere-derived cells for heart regeneration after myocardial infarction (CADUCEUS): a prospective, randomized phase 1 trial. Lancet 379: 895-904.

29. Takashima S, Tempel D, Duckers HJ (2013) Current outlook of cardiac stem cell therapy towards a clinical application. Heart 99: 1772-1784

30. Hare JM, Traverse JH, Henry TD, Dib N, Strumpf RK, et al. (2009) A randomized, double blinded, placebo controlled, dose escalating study of intravenous adult human mesencyhmal stem cells after acute myocardial infarction. J Am Coll Cariol 54: 2277-2286.

31. Oettgen P, Boyle AJ, Schulman SP, Hare JM (2006) Cardiac stem cell therapy: need for optimization of efficacy and safetly monitoring. Circulation 114: 355-358.

32. Hou D, Youssef EA, Brinton TJ, Zhang P, Rogers P, et al. (2005) Radiolabeled cell distribution after intramyocaridal, intracoronary, and interstitial retrograde coronary venous delivery: implications for current clinical trials. Circulation 112: $1150-1156$

33. Surder D, Manka R, Cicero V, Moccetti T, Rufibach K, et al. (2013) Intracoronary injection of bone marrow derived mononuclear cells, early or late after acute myocardial infarction: effects on global left ventricular function four months results of the SWISS-AMI trial. Circulation 127: 1968-1979.

34. Wollert KC, Drexler H (2005) Clinical application of stem cells for the heart. Circ Res 96: 151-163.

35. Perin EC, Sanz-Ruiz R, Sánchez PL, Lasso J, Pérez-Cano R, et al. (2014) Adipose-derived regenerative cells in patients with ischemic cardiomyopathy: The PRECISE trial. Am Heart J 168: 88-95.

36. Bartunek J, Behfar A, Dolatabadi D, Vanderheyden M, Ostojic M, et al. (2013) Cardiopoietic stem cell therapy in heart failure: the C-CURE (Cardiopoietic stem Cell therapy in heart failURE) multicenter randomized trial with lineage specific biologics. J Am Coll Cariol 61: 2329-2338.

37. Gho JM, Kummeling GJ, Koudstaal S, Jansen Of Lorkeers SJ, Doevendans PA, et al. (2013) Cell therapy, a novel remedy for dilated cardiomyopathy? A systematic review. J Card Fail 19: 494-502.

38. Boyle AJ, Schulman SP, Hare JM, Oettgen P (2006) Is stem cell therapy ready for patients? Stem cell therapy for cardiac repair: ready for the next step. Circulation 114: 339-352.

39. Haider HKh, Ashraf M (2010) Preconditioning and stem cell survival. J Cardiovasc Transl Res 3: 89-102. 